\title{
Future Climate Change on Energy Consumption of Office Buildings in Different Climate Zones of China
}

\author{
Yuehao Chen', Mingcai Li' ${ }^{1 *}$, Mingming Xiong1, Jingfu Cao${ }^{1}, \mathrm{Ji} \mathrm{Li}^{2}$ \\ ${ }^{1}$ Tianjin Climate Center, Tianjin 300074, China \\ ${ }^{2}$ China Academy of Building Research, Beijing 100013, China
}

Received: 27 March 2017

Accepted: 28 May 2017

\begin{abstract}
We quantitatively evaluated the future energy consumption of office buildings for cooling and heating in Harbin, Tianjin, Shanghai, and Guangzhou, which represented different building climate zones in China. The results show that office buildings in different building climate zones have a decreasing trend of heating load and an increasing trend of cooling load. For the change of heating load, the fastest decreasing rate is in Harbin, located in a severe cold zone with 32.9 and $81.5 \mathrm{~W} / \mathrm{m}^{2}$ per 10 years for low and medium forcing, respectively, followed by Shanghai, located in a hot summer and cold winter zone, and Tianjin, located in the cold zone. For the change of cooling load, the fastest increasing rate is in Shanghai, with 76.3 and $124.0 \mathrm{~W} / \mathrm{m}^{2}$ per 10 years for low and medium forcing, respectively, followed by Guangzhou, located in a hot summer and warm winter zone. By contrast, the increasing rate for the cooling load is relatively slow in Harbin and Tianjin. By comparing with the past 50 years (1961-2010), total energy consumption in Harbin will decrease in the future during two periods (2011-50 and 2011-2100), with $1.93 \%$ and $1.85 \%$ reduction in $2011-50$ for low and medium forcing, and $2.16 \%$ and $2.72 \%$ reduction in 2011-2100, respectively.
\end{abstract}

Keywords: different building climate zones, office buildings, TRNSYS, energy consumption of buildings, climate change

\section{Introduction}

With the continuous development of economics, the energy consumption of buildings exhibits an annual increasing trend [1-2], which has received significant attention from governments and relevant departments [3].

*e-mail: mingcaili_qhzx@163.com
Some reports show that the energy consumption of heating in winter and cooling in summer has played a dominant role in the total energy consumption of buildings [4-5]. This energy consumption is subject to the considerable influence of climate change and enables potential energy savings [6]. Studies on building energy savings and climate change have important significance in reducing terminal energy consumption and greenhouse gas emissions, which will be helpful to ensure the sustainable development of energy resources. 
Research on the energy efficiency of buildings in China began in the early 1980s [7]. With rapid economic development, new buildings were continuously built in China, and existing buildings with high energy consumption account for a very large proportion [8]. The general energy savings level in China has a gap compared with developed countries [9]. The sustained increase in energy consumption is affected by the constant improvement in economic development and residential living level, and it is also closely related to local climate conditions. The fifth assessment report of the Intergovernmental Panel on Climate Change (IPCC) predicted that the global surface temperature will increase $0.3-4.8^{\circ} \mathrm{C}$ by the end of the $21^{\text {st }}$ century, based on the level at the beginning of this century [10]. To our knowledge, buildings, once built, may last many years. According to the Unified Standard for Reliability Design of Building Structures of China (2001; GB50068-2001), important buildings have a long life span of 100 years while normal buildings have a life span of 50 years. Therefore, the influence of future climate change on the energy consumption of buildings should be considered to enable society to adapt to this change.

Many previous studies applied the data of future climate factors to analyze the energy consumption of buildings and showed that the future energy consumption of heating will have a decreasing trend, whereas the energy consumption of cooling will significantly increase [11-13]. Wan et al. [14] studied the variation in the future energy consumption of office buildings in Hong Kong, and found that the energy consumption of buildings will increase by $6.6 \%$ and $8.1 \%$ by the end of the $21^{\text {st }}$ century in low and medium emission scenarios, respectively, compared with 1979-2008. To study the potential influence of climate change on the energy consumption of heating, Zmeureanu et al. [15] analyzed 11 selected samples of existing buildings and found that the energy consumption of heating in the future (2040-69) will decrease by 7.9-16.9\% compared with the past (1961-1990). Li et al. [16] revealed that the heating load of office buildings and residential buildings in Tianjin in northern China would have a decreasing trend, and that the cooling load would have an increasing trend in 90 years, but the variation rate differs for different energy-saving levels. There are obvious climatic differences between different cities in China, a large country, and variations in the future energy consumption of buildings in different climate zones with future climates may differ [17].

According to previous studies, the energy consumption of building heating will generally have a decreasing trend, and the energy consumption of cooling increases. But it is unknown how future building energy consumption will respond to the continuing climate change in different climate zones [18]. In the background of climate change, the current design standard of heating, ventilating, and air conditioning (HVAC) cannot satisfy the demands of development of building energy efficiency. HVAC should be designed and planned in accordance with local climate conditions and climate change characteristics. In this study, a correlation relationship was established between the principal components of climatic factors and energy consumption, and combined the data of climate predictions for the low and medium forcing to predict the variation trend of energy consumption in office buildings of representative cities in different climate zones for the next 100 years. The aims of this study were to quantify the future energy consumption variations in different climate zones in China, which can provide a scientific basis for government or building designers to formulate energy savings and emission reduction policies or measures.

\section{Material and Methods}

\section{Study Area}

China is a vast country covering 9.6 million $\mathrm{km}^{2}$. There are five major climate zones across China, namely severe cold, cold, hot summer and cold winter, mild and hot summer, and warm winter zones [19]. Harbin, Tianjin, Shanghai, Kunming, and Guangzhou were selected to represent severe cold, cold, hot summer and cold winter, mild, and hot summer and warm winter zones, respectively (Fig. 1). The climate of Kunming is comfortable in the whole year, and no mandatory requirements of building heating and cooling and no limit for exterior-protected structures, so the energy consumption of office buildings in Kunming could not be simulated. Therefore, the energy consumption in Kunming was not analyzed in this study.

\section{Simulation of Building Energy Consumption}

Today there are many commercial programs for the simulating building energy consumption: TRNSYS, EnergyPlus, Energy-10, DOE-2, RADCOOL, BLAST, BSim, ESP-r, and so on. The multiyear simulation of building energy consumption was carried out using transient system simulation program (TRNSYS) software. TRNSYS was designed by the Institute of Building Technology and Solar Energy Utilization at the University

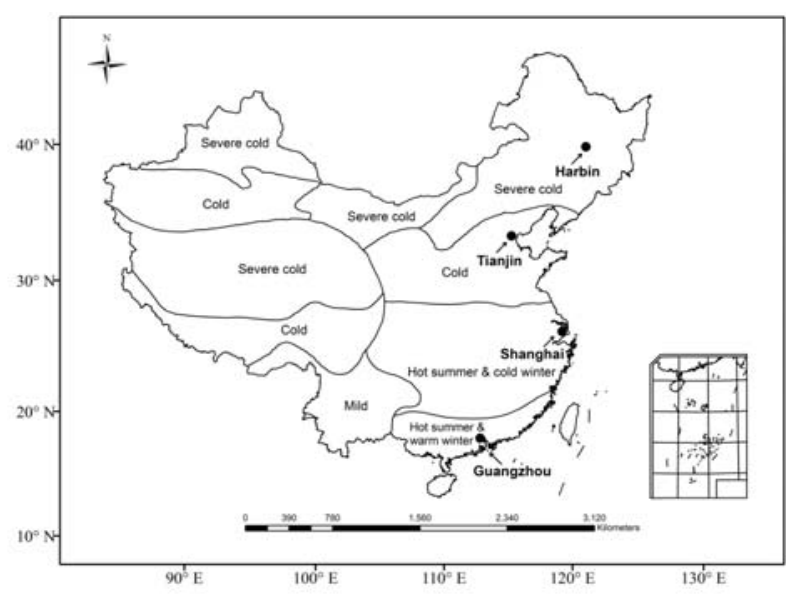

Fig. 1. Overall view of different building climates and geographical distribution of the selected cities. 
of Wisconsin in the United States. TRNSYS has been commercially available since 1975 and can simulate data using the modular analysis method [20]. The superiority of TRNSYS is to solve complex energy system problems by calling a series of modules with specific functions. These modules will be integrated together as a visual interface known as the TRNSYS simulation studio, and building parameters are input through a dedicated visual interface [16]. TRNSYS is well suited to analyze solar energy, thermal response of buildings, renewable energy systems, etc. In the present study, the simulation of energy consumption of heating and cooling inside buildings by TRNSYS had relatively high accuracy and reliability, and could be used to estimate the energy consumption of buildings [21]. The energy consumption of office buildings generally accounts for a large portion of total energy consumption of buildings, and office buildings were therefore selected for analysis. The selected typical office building has a total of 22 floors, with total construction area of $32,200 \mathrm{~m}^{2}$ and a height of $98 \mathrm{~m}$. The simulation process of TRNSYS is subject to the joint influence of building design parameters and meteorological parameters. The building parameters input to TRNSYS are listed in Table 1. The meteorological parameters include hourly dry bulb temperature (DBT), relative humidity $(\mathrm{RH})$, wind direction, wind speed, and global solar radiation (GSR) data at national meteorological observation stations in Harbin, Tianjin, Shanghai, and Guangzhou from 1961-2010. Recorded four times per day during 1981-2005, DBT and relative humidity (RH) (having been recorded hourly since 2006) were used to obtain the hourly data by using the cubic spline interpolation method and then to obtain WBT by corresponding DBT and RH. The hourly solar radiation was first obtained through daily total solar radiation by using the Collores-Perein and Rabl model (CPR model) [22]. The generated hourly solar radiation data were then adjusted for rainy, foggy, and sunny weather conditions. The CPR model and calculating methods can be found $\mathrm{Li}$ et al. [23].

\section{Major Climatic Variables}

In this study, DBT, WBT, and GSR were considered as the climatic variables affecting the energy consumption of buildings [24]. Wan et al. [19] reported that the MIROC3.2-H model had a relatively excellent simulation performance of temperature and humidity in different climate zones in China. In this study, the MIROC5 model in the Coupled Model Intercomparison Project phase 5 (CMIP5) from IPCC AR5 (IPCC Fifth Assessment Report) was selected to obtain the future (2011-2100) three climatic variables, and the historical (1961-2010) data were from the local meteorological station. The monthly data over a total of 140 years in the two time periods from 1961-2010 (history) and 2011-2100 (future) were analyzed, including DBT, RH, and GSR. The WBT data was calculated from the DBT and corresponding RH.

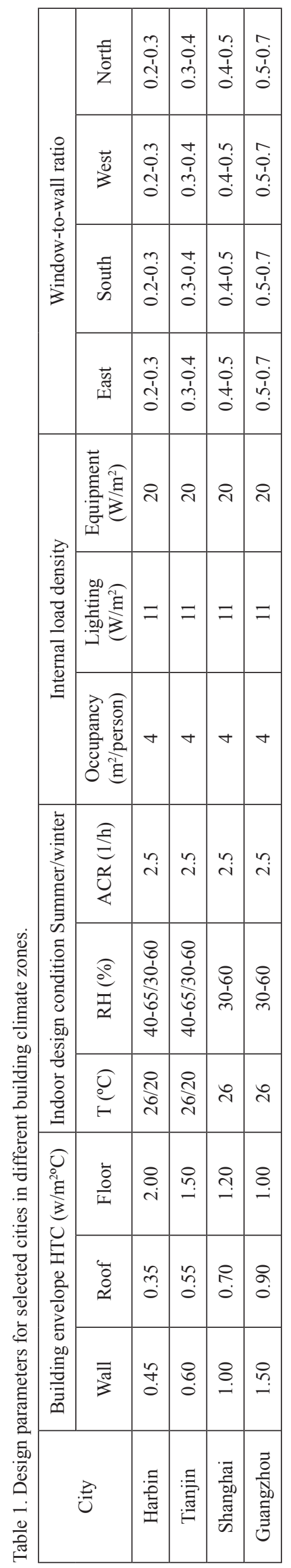


The principal component analysis (PCA) that can integrate the effects of DBT, WBT, and GSR was used to determine the relationships between the climatic variables and the energy consumption of buildings [25], and then the regression models between PCA and corresponding monthly energy consumption can be obtained. Finally, the future energy consumption of buildings could be predicted by using the regression models.

\section{Future Variation of Climatic Factors and PCA}

Table 2 shows the annual averages of the three climatic variables (DBT, WBT, and GSR) in different cities. DBT, WBT, and GSR data from 2011 to 2100 are in two emissions scenarios, i.e., the IPCC Representative Concentration Pathways 2.6 (RCP2.6, low forcing) and 6.0 (RCP6.0, medium forcing), namely the radiation forcing in 2100 is $2.6 \mathrm{~W} / \mathrm{m}^{2}$ and $6.0 \mathrm{~W} / \mathrm{m}^{2}$, respectively. Significant increasing trends are found for the future DBT and WBT in four cities, but the GSR does not exhibit a significant change. Compared with 1961-2010, the annual mean DBT in Harbin increases by $1.5^{\circ} \mathrm{C}$ and $1.8^{\circ} \mathrm{C}$, and the annual mean WBT increases by $1.4^{\circ} \mathrm{C}$ and $1.8^{\circ} \mathrm{C}$ for low and medium forcing during 2011-2100, respectively. The annual mean DBT in Shanghai increases by $1.7^{\circ} \mathrm{C}$ and $1.8^{\circ} \mathrm{C}$, and the annual mean WBT increases by $1.5^{\circ} \mathrm{C}$ and $1.6^{\circ} \mathrm{C}$ for low and medium forcing during 2011-2100, respectively.

Table 2. Annual average values of dry bulb temperature (DBT), wet bulb temperature (WBT), and global solar radiation (GSR) during different periods.

\begin{tabular}{|c|c|c|c|c|}
\hline City & Scenario & $\begin{array}{l}\text { DBT } \\
\left({ }^{\circ} \mathrm{C}\right)\end{array}$ & $\begin{array}{l}\text { WBT } \\
\left({ }^{\circ} \mathrm{C}\right)\end{array}$ & $\begin{array}{c}\mathrm{GSR} \\
\left(\mathrm{MJ} / \mathrm{m}^{2}\right)\end{array}$ \\
\hline \multirow{3}{*}{ Harbin } & $1961-2010$ & 4.4 & 1.7 & 12.9 \\
\hline & $\begin{array}{c}2011-2100 \\
\text { (RCP2.6) }\end{array}$ & 5.9 & 3.1 & 13.2 \\
\hline & $\begin{array}{c}2011-2100 \\
\text { (RCP6.0) }\end{array}$ & 6.2 & 3.5 & 12.7 \\
\hline \multirow{3}{*}{ Tianjin } & $1961-2010$ & 13.0 & 9.2 & 13.8 \\
\hline & $\begin{array}{c}2011-2100 \\
\text { (RCP2.6) }\end{array}$ & 14.6 & 10.8 & 14.1 \\
\hline & $\begin{array}{c}2011-2100 \\
\text { (RCP6.0) }\end{array}$ & 14.6 & 11.0 & 13.5 \\
\hline \multirow{3}{*}{ Shanghai } & $1961-2010$ & 16.4 & 13.9 & 12.6 \\
\hline & $\begin{array}{c}2011-2100 \\
\text { (RCP2.6) }\end{array}$ & 18.1 & 15.4 & 13.4 \\
\hline & $\begin{array}{c}2011-2100 \\
\text { (RCP6.0) }\end{array}$ & 18.2 & 15.5 & 12.6 \\
\hline \multirow{3}{*}{ Guangzhou } & $1961-2010$ & 22.2 & 19.3 & 11.7 \\
\hline & $\begin{array}{c}2011-2100 \\
\text { (RCP2.6) }\end{array}$ & 23.6 & 20.5 & 12.7 \\
\hline & $\begin{array}{c}2011-2100 \\
\text { (RCP6.0) }\end{array}$ & 23.6 & 20.5 & 11.6 \\
\hline
\end{tabular}

A dataset containing 50 years (1961-2010) of measured data from the meteorological stations and 90 years (2011-2100) of predicted data from the MIROC5 model for low and medium forcing was established, which contained 140 years of monthly DBT, WBT, and GSR. The dataset was used to conduct PCA (Table 3). For low and medium forcing, the cumulative explained variance of the first principal component in the four cities exceeded $80 \%$, and the eigenvalues of both the second principal component and third principal component were less than 1. Therefore, the first principal component was reserved, and derived a new variable $Z$ that was constituted via the linear combination of three variables of climatic factors, namely $Z=T_{d} \times a+T_{w} \times b+R_{S} \times c$. The new variable $Z$ could be applied to estimate energy consumption in past and future years.

\section{Regression Analysis of Energy Consumption and Principal Component $\mathrm{Z}$}

According to the relevant regulations on heating in China and the actual situation in different climate zones, the air-conditioning and heating periods were divided in four cities of different climate zones. The cooling period in summer is June-September in Tianjin, Shanghai, and Guangzhou, and June-August in Harbin. The heating period in winter is October 20 to April 20 of the next year in Harbin, November 15 to March 15 of the next year in Tianjin and Shanghai, and does not exist in Guangzhou. The monthly simulated energy consumption of TRNSYS in four cities during 1961-2000 and the principal components $\mathrm{Z}$ in corresponding months were used to carry out regression analysis, the regression models were then established (Table 4). It can be seen that the regression models of four cities have a rather high coefficient of determination $\left(\mathrm{R}^{2} \geq 0.7\right)$, indicating strong correlation between simulated energy consumption and the corresponding principal component. The heating load is negatively correlated with the principal component $\mathrm{Z}$ in all climate zones. When the corresponding $\mathrm{Z}$ increases one unit, the heating load in Harbin will decrease $17.80 \mathrm{~W} / \mathrm{m}^{2}$ and $17.84 \mathrm{~W} / \mathrm{m}^{2}$ for the low and medium forcing, $15.94 \mathrm{~W} / \mathrm{m}^{2}$ and $16.04 \mathrm{~W} / \mathrm{m}^{2}$ in Tianjin, $17.46 \mathrm{~W} / \mathrm{m}^{2}$ and $17.54 \mathrm{~W} / \mathrm{m}^{2}$ in Shanghai. By contrast, a positive correlation is observed between the cooling load and the principal component $\mathrm{Z}$ in all the climate zones. The cooling load in Harbin will increase $21.51 \mathrm{~W} / \mathrm{m}^{2}$ and $21.60 \mathrm{~W} / \mathrm{m}^{2}$ for the low and medium forcing, with one unit increase of the corresponding $\mathrm{Z}$, increasing $25.74 \mathrm{~W} / \mathrm{m}^{2}$ and $26.00 \mathrm{~W} / \mathrm{m}^{2}$ in Tianjin, $30.12 \mathrm{~W} / \mathrm{m}^{2}$ and $30.42 \mathrm{~W} / \mathrm{m}^{2}$ in Shanghai, and $28.78 \mathrm{~W} / \mathrm{m}^{2}$ and $29.15 \mathrm{~W} / \mathrm{m}^{2}$ in Guangzhou.

To validate the performance of the regression models, an error analysis was conducted by comparing the simulated energy consumption during 2001-10 with those determined from the regression equations. The mean bias error (MBE), normalized mean bias error (NMBE), root mean square error (RMSE), and coefficient of variation of the root mean square error (CVRMSE) were used to 
Table 3. Summary of principal component analysis in selected cities.

\begin{tabular}{|c|c|c|c|c|c|c|c|}
\hline \multirow{2}{*}{ City } & \multirow{2}{*}{ Scenario } & \multirow{2}{*}{ Principal component } & \multirow{2}{*}{ Eigenvalue } & \multirow{2}{*}{$\begin{array}{c}\text { Cumulative explained } \\
\text { variance } / \%\end{array}$} & \multicolumn{3}{|c|}{ Coefficient } \\
\hline & & & & & DBT & WBT & GSR \\
\hline \multirow{6}{*}{ Harbin } & \multirow{3}{*}{$\mathrm{RCP} 2.6$} & 1 & 2.788 & 92.9 & 0.987 & 0.979 & 0.925 \\
\hline & & 2 & 0.210 & 99.9 & & & \\
\hline & & 3 & 0.002 & 100 & & & \\
\hline & \multirow{3}{*}{ RCP6.0 } & 1 & 2.774 & 92.5 & 0.987 & 0.977 & 0.919 \\
\hline & & 2 & 0.225 & 99.9 & & & \\
\hline & & 3 & 0.002 & 100 & & & \\
\hline \multirow{6}{*}{ Tianjin } & \multirow{3}{*}{$\mathrm{RCP} 2.6$} & 1 & 2.686 & 89.5 & 0.984 & 0.967 & 0.884 \\
\hline & & 2 & 0.311 & 99.9 & & & \\
\hline & & 3 & 0.003 & 100 & & & \\
\hline & \multirow{3}{*}{ RCP6.0 } & 1 & 2.645 & 88.2 & 0.982 & 0.964 & 0.866 \\
\hline & & 2 & 0.352 & 99.9 & & & \\
\hline & & 3 & 0.003 & 100 & & & \\
\hline \multirow{6}{*}{ Shanghai } & \multirow{3}{*}{$\mathrm{RCP} 2.6$} & 1 & 2.722 & 90.7 & 0.981 & 0.976 & 0.898 \\
\hline & & 2 & 0.276 & 99.9 & & & \\
\hline & & 3 & 0.002 & 100 & & & \\
\hline & \multirow{3}{*}{ RCP6.0 } & 1 & 2.681 & 89.4 & 0.979 & 0.973 & 0.88 \\
\hline & & 2 & 0.317 & 99.9 & & & \\
\hline & & 3 & 0.002 & 100 & & & \\
\hline \multirow{6}{*}{ Guangzhou } & \multirow{3}{*}{$\mathrm{RCP} 2.6$} & 1 & 2.527 & 84.2 & 0.981 & 0.951 & 0.813 \\
\hline & & 2 & 0.468 & 99.8 & & & \\
\hline & & 3 & 0.006 & 100 & & & \\
\hline & \multirow{3}{*}{ RCP6.0 } & 1 & 2.502 & 83.4 & 0.980 & 0.950 & 0.799 \\
\hline & & 2 & 0.492 & 99.8 & & & \\
\hline & & 3 & 0.006 & 100 & & & \\
\hline
\end{tabular}

evaluate the models. Table 5 shows a summary of the validation results. It can be seen that the regression models could well simulate the heating/cooling load of the four cities, the NMBE ranges from -0.58 to $2.47 \%$, and the CVRMSE ranges from 4.39 to $11.62 \%$. This indicates that the predicted energy consumption from the regression models could well reflect the simulated consumption by TRNSYS, and the regression models can be used to estimate future energy consumption. For simulating the heating load, the best results are obtained for Harbin. For low and medium forcing, the NMBE is $0.87 \%$ and $0.86 \%$, respectively, and the CVRMSE is $4.40 \%$ and $4.39 \%$, respectively. For the simulation of the cooling load, the best simulation results are obtained for Shanghai. For low and medium forcing, the NMBE is $-0.58 \%$ and $-0.49 \%$, respectively, and the CVRMSE is $5.62 \%$ and $5.53 \%$, respectively.

\section{Influence of Climate Change on the Energy Consumption of Office Buildings}

Figs 2-5 shows the variations of the annual average heating load, cooling load, and total energy consumption in the four cities during 1961-2100. There is a decreasing trend of heating load in Harbin, Tianjin, and Shanghai, indicating that the heating load gradually declines as the temperature increases in winter. Conversely, there is an increasing trend of cooling load in all four cities, indicating that the cooling load increases annually. Except for Harbin, an increasing trend is observed for total energy consumption in both Tianjin and Shanghai.

For the variation rates of the heating load and cooling load in the four cities during the future 90 years (20112100) (Figs 2-5), the fastest decreasing rate of the heating load is observed for Harbin, located in the severe cold 
Table 4. Summary of regression analysis of building energy consumption.

\begin{tabular}{|c|c|c|c|c|}
\hline City & Scenario & & Regression Models & $\mathrm{R}^{2}$ \\
\hline \multirow{4}{*}{ Harbin } & \multirow{2}{*}{$\mathrm{RCP} 2.6$} & Heating & $Y=-17.80 x+929.23$ & 0.984 \\
\hline & & Cooling & $Y=21.51 x-810.01$ & 0.723 \\
\hline & \multirow{2}{*}{ RCP6.0 } & Heating & $Y=-17.84 x+928.31$ & 0.984 \\
\hline & & Cooling & $Y=21.60 x-812.17$ & 0.725 \\
\hline \multirow{4}{*}{ Tianjin } & \multirow{2}{*}{$\mathrm{RCP} 2.6$} & Heating & $Y=-15.94 x+768.67$ & 0.917 \\
\hline & & Cooling & $Y=25.74 x-889.74$ & 0.852 \\
\hline & \multirow{2}{*}{ RCP6.0 } & Heating & $Y=-16.04 x+766.76$ & 0.917 \\
\hline & & Cooling & $Y=26.00 x-894.68$ & 0.857 \\
\hline \multirow{4}{*}{ Shanghai } & \multirow{2}{*}{$\mathrm{RCP} 2.6$} & Heating & $Y=-17.46 x+796.89$ & 0.868 \\
\hline & & Cooling & $Y=30.12 x-1128.15$ & 0.948 \\
\hline & \multirow{2}{*}{ RCP6.0 } & Heating & $Y=-17.54 x+795.23$ & 0.869 \\
\hline & & Cooling & $Y=30.42 x-1134.51$ & 0.949 \\
\hline \multirow{4}{*}{ Guangzhou } & \multirow{2}{*}{$\mathrm{RCP} 2.6$} & Heating & - & - \\
\hline & & Cooling & $Y=28.78 x-888.17$ & 0.774 \\
\hline & \multirow{2}{*}{ RCP6.0 } & Heating & - & - \\
\hline & & Cooling & $Y=29.15 x-904.45$ & 0.779 \\
\hline
\end{tabular}

zone, 32.9 and $81.5 \mathrm{~W} / \mathrm{m}^{2}$ per 10 years for low and medium forcing, respectively, followed by Shanghai in the hot summer and cold winter zone, and Tianjin in the cold zone. For the variation of the cooling load, the
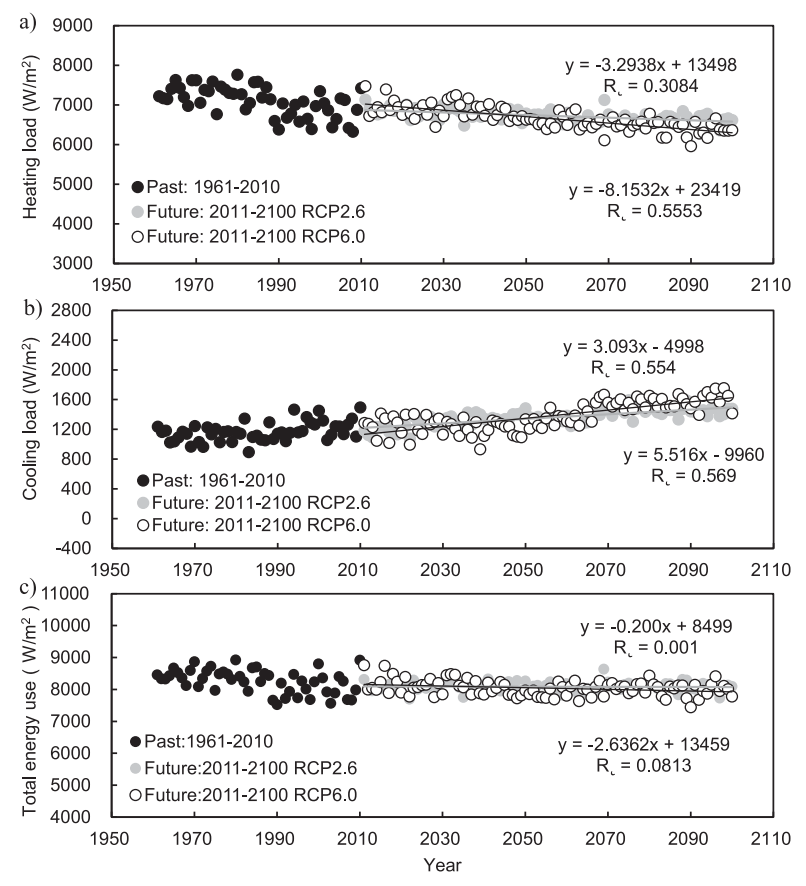

Fig. 2. Long-term trends of annual heating load, cooling load, and total energy use in Harbin.
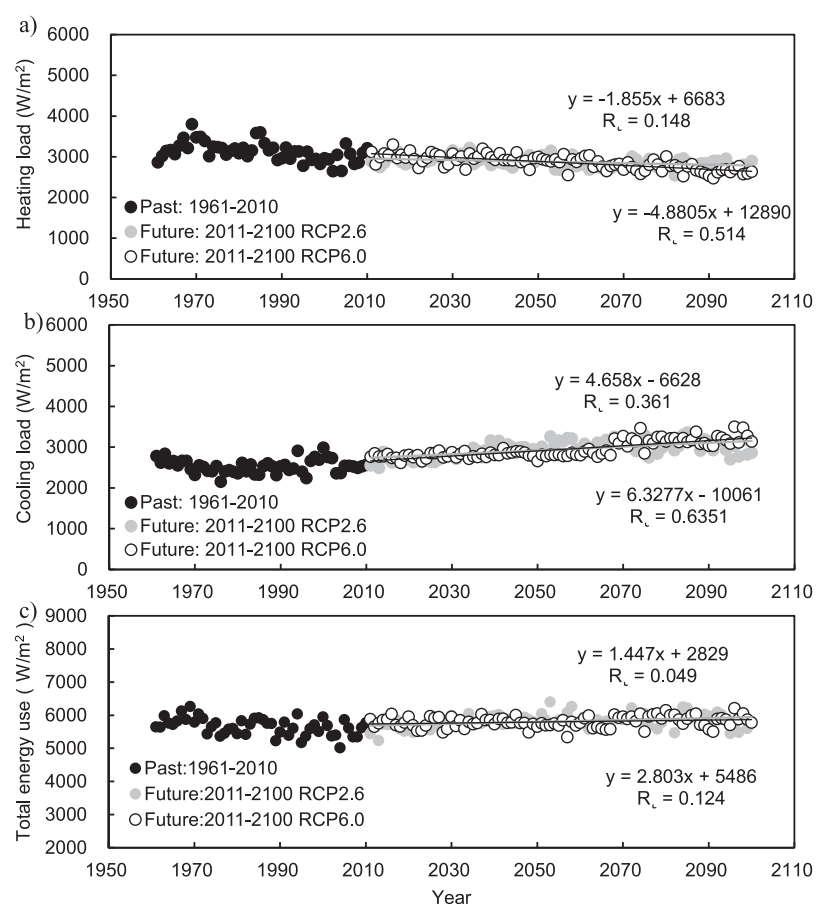

Fig. 3. Long-term trends of annual heating load, cooling load, and total energy use in Tianjin.

fastest increasing rate is observed for Shanghai, at 76.3 and $124.0 \mathrm{~W} / \mathrm{m}^{2}$ per 10 years for low and medium forcing, respectively, followed by Guangzhou in the hot summer and warm winter zone. In Harbin, the decreasing rate of heating load is rather fast, which may indicate a relatively large potential for energy savings in the severe cold zone in

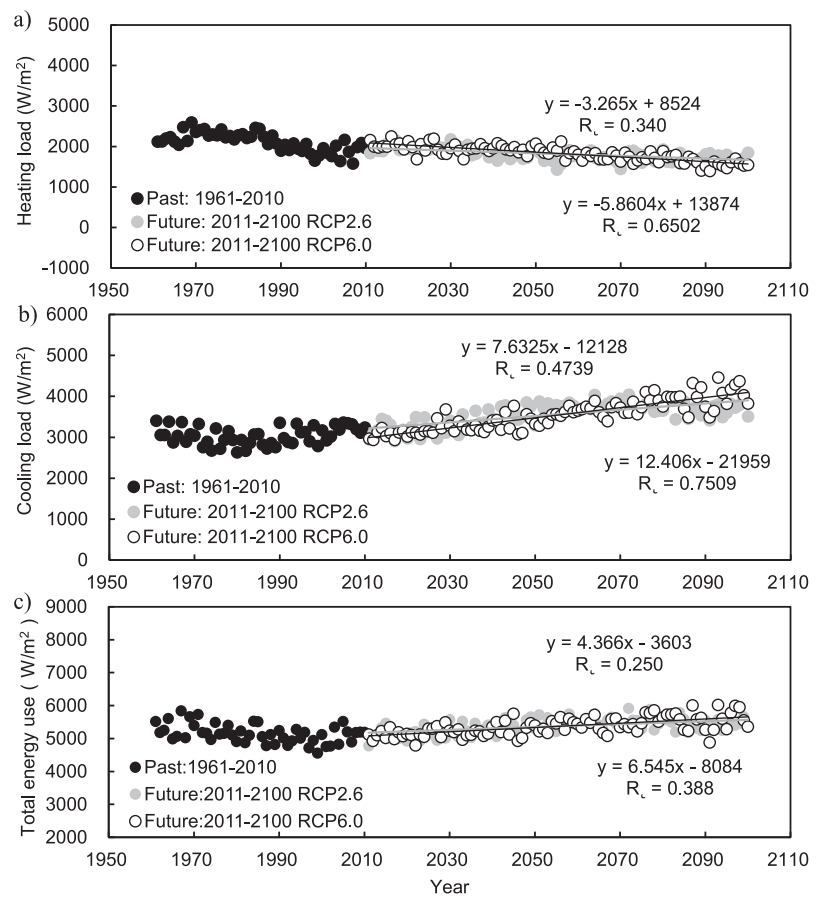

Fig. 4. Long-term trends of annual heating load, cooling load, and total energy use in Shanghai. 


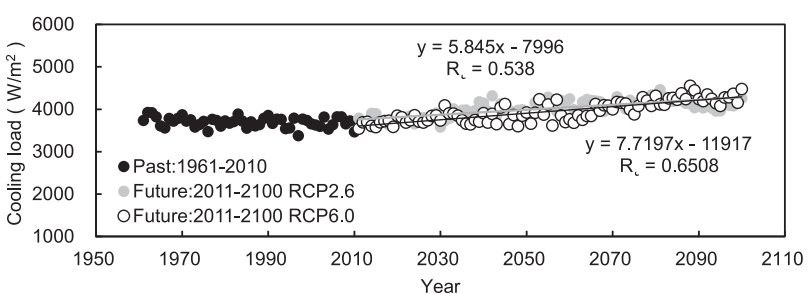

Fig. 5. Long-term trends of annual cooling load in Guangzhou.

the future. Conversely, the increasing rate of cooling load is relatively fast in Shanghai and Guangzhou, indicating a relatively large energy consumption requirement in the hot summer and cold winter and the hot summer and warm winter zones.

To quantify the influence of climate change on the energy consumption of buildings, the variations of heating load, cooling load, and total energy consumption during three time periods (1961-2010, 2011-50, and 2011-2100) were analyzed (Fig. 6). Compared with 1961-2010, the average annual heating load in Shanghai in 2011-50 will decrease $9.66 \%$ and $6.65 \%$ for low and medium forcing, respectively. The average annual heating load in 2011-50 will decrease $6.53 \%$ and $4.83 \%$ in Tianjin and $3.96 \%$ and $2.97 \%$ in Harbin, respectively. The variation trend of the heating load in 2011-2100 is similar to that in 2011-50. Compared with 1961-2010, the average annual heating load in Shanghai in 2011-2100 will decrease 14.30\% and $13.55 \%$ for low and medium forcing, respectively, $8.31 \%$ and $8.66 \%$ in Tianjin, respectively, and $5.18 \%$ and $6.12 \%$ in Harbin, respectively.
Compared with 1961-2010, the average annual cooling load in Tianjin in 2011-50 will increase $11.02 \%$ and $10.61 \%$ for low and medium forcing, respectively; $10.41 \%$ and $4.98 \%$ in Harbin, respectively; $9.71 \%$ and $6.18 \%$ in Shanghai, respectively; and $4.31 \%$ and $1.97 \%$ in Guangzhou, respectively. The average annual cooling load in Shanghai in 2011-2100 will increase $17.24 \%$ and $16.62 \%$ for low and medium forcing, respectively; $16.17 \%$ and $17.92 \%$ in Harbin, respectively; $16.49 \%$ and $16.43 \%$ in Tianjin, respectively; and $8.76 \%$ and $6.90 \%$ in Guangzhou, respectively.

For total energy consumption, a decreasing trend is observed in Harbin. Compared with 1961-2010, the average annual total energy consumption in Harbin in 2011-50 will decrease $1.93 \%$ and $1.85 \%$ for low and medium forcing, and $2.16 \%$ and $2.72 \%$ in $2011-2100$, respectively. In Tianjin and Shanghai, total energy consumption will increase in the next 90 years. Compared with 1961-2010, the average annual total energy consumption in Tianjin in 2011-2050 will increase 1.32\% and $2.07 \%$ for low and medium forcing, respectively; and $2.78 \%$ and $2.56 \%$ in 2011-2100, respectively. In Shanghai, the average annual total energy consumption in 2011-2050 will increase $1.76 \%$ and $0.91 \%$, respectively; and $4.30 \%$ and $4.24 \%$ in $2011-2100$, respectively.

\section{Conclusion and Discussions}

In this study, the principal component analysis of three climatic variables (i.e., DBT, WBT, GSR) was carried out, and a new variable $\mathrm{Z}$ was obtained for low and medium

Table 5. Error analysis of regression models.

\begin{tabular}{|c|c|c|c|c|c|c|}
\hline City & Scenario & & MBE & NMBE (\%) & RMSE & CVRMSE (\%) \\
\hline \multirow{4}{*}{ Harbin } & \multirow{2}{*}{ RCP2.6 } & Heating & 8.52 & 0.87 & 42.90 & 4.40 \\
\hline & & Cooling & 3.78 & 0.92 & 47.75 & 11.62 \\
\hline & \multirow{2}{*}{ RCP6.0 } & Heating & 8.42 & 0.86 & 42.81 & 4.39 \\
\hline & & Cooling & 3.89 & 0.95 & 47.60 & 11.58 \\
\hline \multirow{4}{*}{ Tianjin } & \multirow{2}{*}{$\mathrm{RCP} 2.6$} & Heating & 6.38 & 1.07 & 36.03 & 6.07 \\
\hline & & Cooling & 12.17 & 1.92 & 37.30 & 5.88 \\
\hline & \multirow{2}{*}{ RCP6.0 } & Heating & 6.19 & 1.04 & 35.93 & 6.05 \\
\hline & & Cooling & 12.57 & 1.99 & 36.94 & 5.82 \\
\hline \multirow{4}{*}{ Shanghai } & \multirow{2}{*}{ RCP2.6 } & Heating & 9.33 & 2.47 & 42.10 & 11.13 \\
\hline & & Cooling & -4.61 & -0.58 & 44.98 & 5.62 \\
\hline & \multirow{2}{*}{ RCP6.0 } & Heating & 9.13 & 2.41 & 41.84 & 11.06 \\
\hline & & Cooling & -3.90 & -0.49 & 44.25 & 5.53 \\
\hline \multirow{4}{*}{ Guangzhou } & \multirow{2}{*}{ RCP2.6 } & Heating & - & - & - & - \\
\hline & & Cooling & 17.05 & 1.86 & 48.25 & 5.26 \\
\hline & \multirow{2}{*}{ RCP6.0 } & Heating & - & - & - & - \\
\hline & & Cooling & 17.19 & 1.87 & 48.05 & 5.24 \\
\hline
\end{tabular}



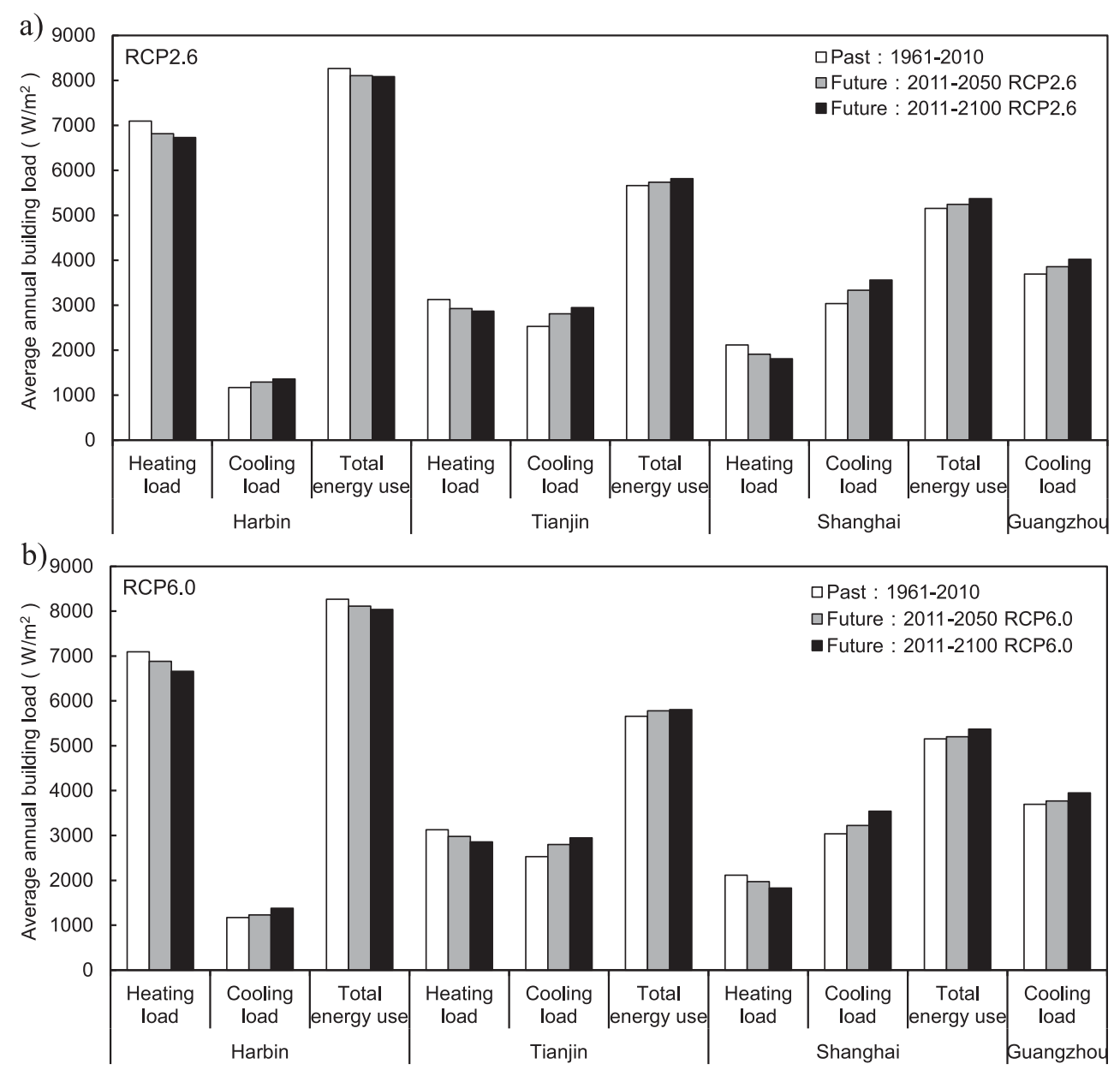

Fig. 6. Annual average value of heating load, cooling load, and total energy use.

forcing. Regression analysis was used to determine the relationships between simulated energy consumption from the TRNSYS model and the corresponding $Z$ value. The regression models were used to predict the future energy consumption of cooling and heating in office buildings of representative cities in different climatic zones. Regression analysis and error analysis indicate that the regression models could well reflect simulated consumption by TRNSYS, and the regression models can efficiently estimate future energy consumption.

Due to the influence of future climate change, the heating load of representative cities in different climate zones shows a decreasing trend, whereas the cooling load shows an increasing trend. By analyzing the variations of the heating and cooling loads in the selected cities, the decreasing rate of heating load is relatively fast in the severe cold zone in the future, indicating a relatively large potential for energy savings. Conversely, the increasing rate of cooling load is relatively fast in the hot summer and cold winter and the hot summer and warm winter zones, which suggests a relatively large energy consumption requirement.

Compared with the past 50 years during 1961-2010, the heating load will decrease and cooling load will increase in all the climate zones in 2011-50 and 20112100. However, total energy consumption shows different changing patterns in the different climate zones. The average annual total energy consumption in the severe cold zone in 2011-50 and 2011-2100 shows a decreasing trend for low and medium forcing, whereas total energy consumption in other climate zones shows an increasing trend. This indicates that the reduction in energy consumption of heating would outweigh the increase in energy consumption of cooling in cities located in severe cold areas in future years, and vice versa in the cities located in other climate zones. This is consistent with previous studies $[19,26]$.

Therefore, the future design of buildings should consider future climate conditions, and make a reasonable prospective layout or design so that the design of buildings adapts to future climate change. This study revealed that there are distinct differences in the future heating and cooling energy consumption variations for the office buildings in different climate zones. In the design of air conditioning capacity, local climate conditions and changing characteristics should be considered to reduce energy consumption during the operation of air conditioners as well as to improve the environmental comfort inside buildings. It is necessary to point out that this study was based on the simulation of typical office building energy consumption. In fact, there are some differences between the selected typical office building and the actual building, 
such as the number of people or computers in the building and the running time of air conditioning. Therefore, the simulated energy consumption of a typical building does not entirely reflect the real energy consumption of a building, which needs to be checked in practice. In addition, only office buildings were selected to determine the effect of future climate change on energy consumption. Further studies should therefore concern other building types, such as commercial buildings that also have large energy consumption.

\section{Acknowledgements}

This work was financially supported by the Climate Change Special Funding (CCSF201423, CCSF201614) project of the China Meteorological Bureau, the "Study on Microclimate Improvement of Tianjin Sino-Singapore Eco-city" science and technology cooperation project between China and Singapore, and the Research and Innovation Team on Urban Climate Assessment of Beijing Meteorological Bureau.

\section{References}

1. LANG S. Current situation and progress of energy efficiency design standards in buildings in China. Refrigeration, Air Conditioning and Electric Power Machinery, 23 (3), 1, 2002 [In Chinese].

2. CAI W.G., WU Y., ZHONG Y., REN H. China building energy consumption: Situation, challenges and corresponding measures. Energy Policy, 37, 2054, 2009.

3. YAO R.M., LI B.Z., STEEMERS K. Energy policy and standard for built environment in China. Renewable Energy, 30, 1973, 2005.

4. LAM J.C., TSANG C.L., YANG L., LI D.H.W. Weather data analysis and design implications for different climatic zones in China. Building and Environment, 40 (2), 277, 2005.

5. LAM J.C., WAN K.K.W., TSANG C.L., YANG L. Building energy efficiency in different climates. Energy Conversion and Management, 49 (8), 2354, 2008.

6. DOLINAR M., VIDRIH B., KAJFEZ L., MEDVED S. Predicted changes in energy demands for heating and cooling due to climate change. Physics and Chemistry of the Earth, 35, 100, 2010.

7. WENG L.F., ZHANG N., CHEN J.P. Thinking of energy efficiency design standards under current building energy consumption in China. Refrigeration and Air Conditioning, 25 (1), 10, 2011 [In Chinese].

8. WANG S.P. The energy consumption of architecture in our nation. Shanxi Architecture, 33(35), 269, 2007 [In Chinese].

9. Tsinghua University Building Energy Research Center. 2010 Annual report on China building energy efficiency. China Architecture \& Building Press: Beijing, China, 2010 [In Chinese].

10. IPCC. Summary for Policymakers. In: Climate Change 2013: The Physical Science Basis. Contribution of Working Group
I to the Fifth Assessment Report of the Intergovernmental Panel on Climate Change. Cambridge University Press: Cambridge, UK, 2013.

11. BERGER T., AMANN C., FORMAYER H., KORJENIC A., POSPISCHAL B., NEURURER C., SMUTNY R. Impacts of climate change upon cooling and heating energy demand of office buildings in Vienna, Austria. Energy and Buildings, 80, 517, 2014.

12. DODOO A., GUSTAVSSON L., BONAKDAR F. Effects of future climate change scenarios on overheating risk and primary energy use for Swedish residential buildings. Energy Procedia, 61, 1179, 2014.

13. WONG S.L., WAN K.K.W., LI D.H.W., LAM J.C. Impact of climate change on residential building envelope cooling loads in subtropical climates. Energy and Buildings, 42, 2098, 2010.

14. WAN K.K.W., LI D.H.W., LAM J.C. Assessment of climate change impact on building energy use and mitigation measures in subtropical climates. Energy, 36 (2), 1404, 2011.

15. ZMEUREANU R., RENAUD G. Estimation of potential impact of climate change on the heating energy use of existing houses. Energy policy, 36 (1), 303, 2008.

16. LI M.C., GUO J., TIAN Z., SHI J., XIONG M.M., XIANG C. Future climate change and building energy demand in Tianjin, China. Building Services Engineering Research \& Technology, 35 (4), 362, 2014.

17. CHOW D.H.C., KELLY M., DARKWA J. The effects of future climate change on energy consumption in residential buildings in China. Journal of Power and Energy Engineering, 1, 16, 2013

18. WANG X.M., CHEN D., REN Z.G. Assessment of climate change impact on residential building heating and cooling energy requirement in Australia. Building and Environment, 45, 1663, 2010.

19. WAN K.K.W., LI D.H.W., LIU D.L., LAM J.C. Future trends of building heating and cooling loads and energy consumption in different climates. Building and Environment, 46, 223, 2011.

20. DATTA G. Effect of fixed horizontal louver shading devices on thermal performance of building by TRNSYS simulation. Renewable Energy, 23, 497, 2001.

21. LI M.C., SHI J., GUO J., CAO J.F., NIU J.D., XIONG M.M. Climate impacts on extreme energy consumption of different types of buildings. PloS ONE, 10 (4), 1, 2015.

22. SONG F.T., ZHU Q.F., JIANG Y. Building environment design simulation software DeST (5): generation of the values of the extraneous factors influencing building thermal processes. HV \& AC, 34 (11), 52, 2004 [In Chinese].

23. LI M.C., CAO J.F., GUO J., NIU J.D., XIONG M.M. Response of energy consumption for building heating to climate change and variability in Tianjin City, China. Meteorological Applications, 23, 123, 2016.

24. LI M.C., XIONG M.M., REN Y., GUO J., TIAN Z. Impact of climate change on office building energy consumption for cooling and heating in Tianjin, China. Advances in Climate Change Research, 9 (6), 398, 2013 [In Chinese].

25. STORCH H.V., ZWIERS F.W. Statistical analysis in climate research. Cambridge: Cambridge University Press, 1999.

26. WANG H.J., CHEN Q.Y. Impact of climate change heating and cooling energy use in buildings in the united states. Energy and Buildings, 82, 428, 2014. 